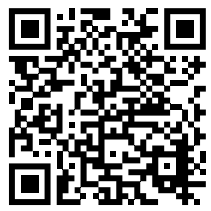

\section{The $\mathrm{U}$ wave: an ignored wave filled with information}

\author{
Onda U: una onda olvidada llena de información
}

\author{
Laura Duque-González,* Maria C Gaviria-Aguilar,* \\ Laura Lopera-Mejía, ${ }^{\ddagger}$ Mauricio Duque-Ramírez ${ }^{\S}$
}

\section{ABSTRACT}

The $\mathrm{U}$ wave was first described over more than 100 years. However, numerous hypothesis about its origin and clinical significance still exist. It corresponds to the sixth wave of the electrocardiogram (ECG), and its visibility depends, among others, on the heart rate, but it may be absent in $50-75 \%$ of cases. Its origin is a cause of debate; there are four crucial hypotheses about its genesis: 1) repolarization of purkinje fibers, 2) repolarization of papillary muscles, 3) M cells theory, and 4) mechanoelectrical theory. Variants of the $U$ wave are prominent and inverted. The inverted $\mathrm{U}$ wave is associated with hypertension, coronary heart disease or valvular disease. The prominent $U$ wave is related to bradycardia, hypokalemia, hypothermia, long QT syndrome or with the use of some medication like class Ia and III antiarrhythmics.

\section{RESUMEN}

La onda U se describió por primera vez hace más de 100 años. Sin embargo, aún existen numerosas hipótesis sobre su origen e importancia clínica. Corresponde a la sexta onda del Electrocardiograma (ECG), su visibilidad depende, entre otras cosas, de la frecuencia cardíaca, pero puede estar ausente en el 50-75\% de los casos. Su origen es motivo de debate; existen cuatro hipótesis cruciales sobre su génesis: 1) repolarización de las fibras de Purkinje, 2) repolarización de los músculos papilares, 3) teoría de las células $M, y$ 4) teoría mecanoeléctrica. Las variantes de la onda U son: prominente e invertida. La onda U invertida se asocia con hipertensión, enfermedad coronaria o enfermedad valvular. La onda $U$ prominente está relacionada con bradicardia, hipocalemia, hipotermia, síndrome de QT largo o con el uso de algunos medicamentos como los antiarritmicos de clase Ia y III.
* Internist. Cardiology

Fellow at CES

University.

$\$$ General physician,

CES Cardiología.

$\S$ Cardiologist-

Electrophysiologist.

CES Cardiología,

CES University.

Medellín, Antioquia.

Colombia.

Received:

16/02/2021

Accepted:

16/07/2021

\section{INTRODUCTION}

M ore than 100 years ago, Willem Einthoven described the first five waves of the electrocardiogram (ECG) using a capillary electrometer, but it was some years later with the invention of the string galvanometer when he identified the sixth deflection of the ECG, the one following the $T$ wave and he named it the $U$ wave. ${ }^{1}$ Nevertheless, there was neither a definition nor description of its normal characteristics, ${ }^{2}$ and it was believed that the $U$ wave represented currents generated by late repolarization of some areas of the ventricular myocardium..$^{3,4}$

Despite its longstanding description, there are no unified criteria nor definition, and there are still lots of uncleared hypotheses about its origin. We know so far that the presence of a $U$ wave can be a normal or pathological finding that can be associated with arterial hypertension, valvular disease, ischemic coronary disease if it is an inverted $U$ wave. In the case of a prominent $U$ wave, it is associated with hypokalemia, hypothermia, long QT syndrome and some antiarrhythmics. In this article, we will review these findings and their possible pathological significance. ${ }^{5}$

\section{MORPHOLOGY AND NORMAL CHARACTERISTICS}

The $U$ wave corresponds to the fourth phase of the action potential. It happens during

How to cite: Duque-González L, Gaviria-Aguilar MC, Lopera-Mejía L, Duque-Ramírez M. The U wave: an ignored wave filled with information. Cardiovasc Metab Sci. 2021; 32 (4): 197-205. https://dx.doi.org/10.35366/102771 
the protodiastolic period of the cardiac cycle and matches the second or third cardiac sounds. ${ }^{6}$

The $U$ wave is not constantly seen, and it is absent in $50-75 \%$ of cases. ${ }^{6}$ Its visibility on the ECG depends on the heart rate, and it is evident in $90 \%$ of cases with heart rates below $65 \mathrm{bpm}$ (beats per minute), and its rarely seen with rates over $95 \mathrm{bpm} .5,7,8$ It is also more evident under some special conditions like hypokalemia, advanced age, and medications such as class la antiarrhythmics and amiodarone. ${ }^{8}$

Surawicsz meticulously described its typical features, and after, were widely reproduced..$^{5,9}$ The $U$ wave begins after the end of the $T$ wave and before the $\mathrm{P}$ wave of the following cardiac cycle; $6,7,10$ it is usually better visualized in leads $\mathrm{V} 2$ and $\mathrm{V} 3,{ }^{6-8}$ and in normal conditions, has the same polarity as the T wave. ${ }^{11}$

The standard duration of the $U$ wave in adults is around $170 \pm 30 \mathrm{~ms}$, and its amplitude is in average $11 \%$ of T wave's amplitude (ranges from 3 to $24 \%$ ); the morphology is usually monophasic positive or negative deflection, but it may be biphasic, and it has an asymmetric shape with a rapid ascending limb and a slower descending limb. 5,6,8

The $\mathrm{T}-\mathrm{U}$ junction is situated at or close to the isoelectric baseline. However, it may slightly deviate; with heart rates between 50-100 bpm, the distance from the end of $\mathrm{T}$ wave to the apex of $U$ wave is between 90 to $110 \mathrm{~ms}$, and from the end of $\mathrm{T}$ wave to the end of the $U$ wave 160 to 230 ms. $^{5,6}$

Accurate measurement of the QT interval is crucial, when the $T$ and the $U$ waves are easily identifiable the separation of them is not difficult, the end of the T wave is evident. The confusion appears when the T wave is notched, because its second peak can be mistaken with the $U$ wave; to differentiate them, another lead where the $T$ wave is not notched, or a lead without $U$ wave could be useful. It is helpful to know that the distance between $\mathrm{T}$ wave peaks is usually less than $150 \mathrm{~ms}$, in contrast to the distance between the first $\mathrm{T}$ peak and the $U$ wave peak that is more than $150 \mathrm{~ms}$. Another important concept is the $\mathrm{QT}+\mathrm{U}$ or $\mathrm{Q}$ $(T+U)$ interval. It describes the fusion of these segments in the ECG and mostly occurs in the circumstances when QT measures more than $100 \mathrm{~ms}$, so the $\mathrm{T}$ wave masks the $\mathrm{U}$ wave. ${ }^{5,12}$

\section{THE HYPOTHESIS OF THE ORIGIN}

The genesis of the $U$ wave is not clear yet; four major theories that try to explain it.

\section{Repolarization of intraventricular conduction system}

Hoffman and Cranefield first described the theory of repolarization of Purkinje fibers, and it was based on the fact that the action potential of these fibers is the longest of all the heart fibers. ${ }^{13}$ Later on, Watanabe found a close relationship between the $U$ wave and Purkinje repolarization in a series of experiments with canines and canine Purkinje fibers from ventricular muscle tissue under conditions known to accentuate the $U$ wave as hypokalemia, hypothermia, administration of quinidine, and bradycardia. ${ }^{14}$ However, there are many arguments against this theory, like the ones listed by Surawicz. He believed

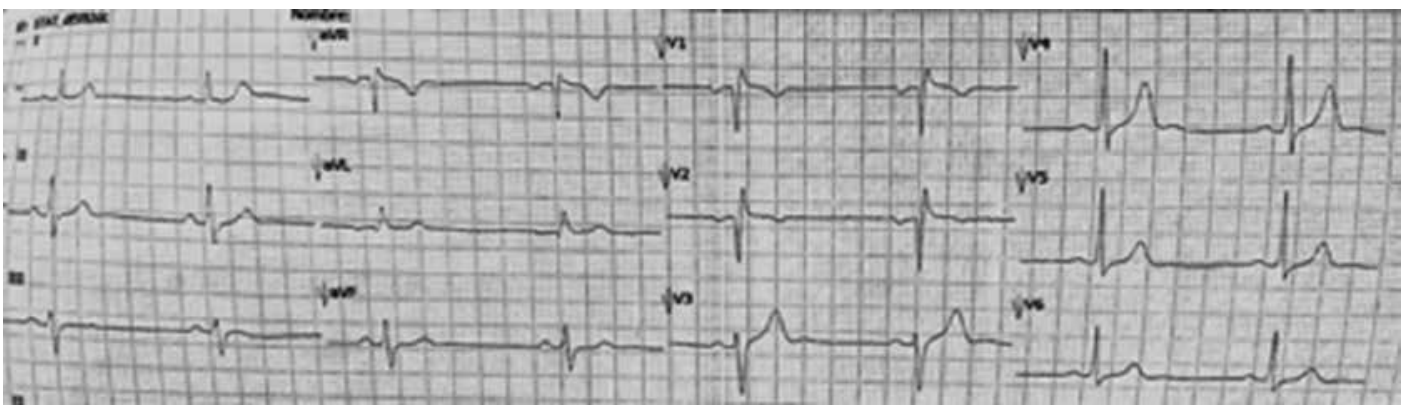

Figure 1: Normal U waves in leads V3 and V4 in a patient with sinus bradycardia. 


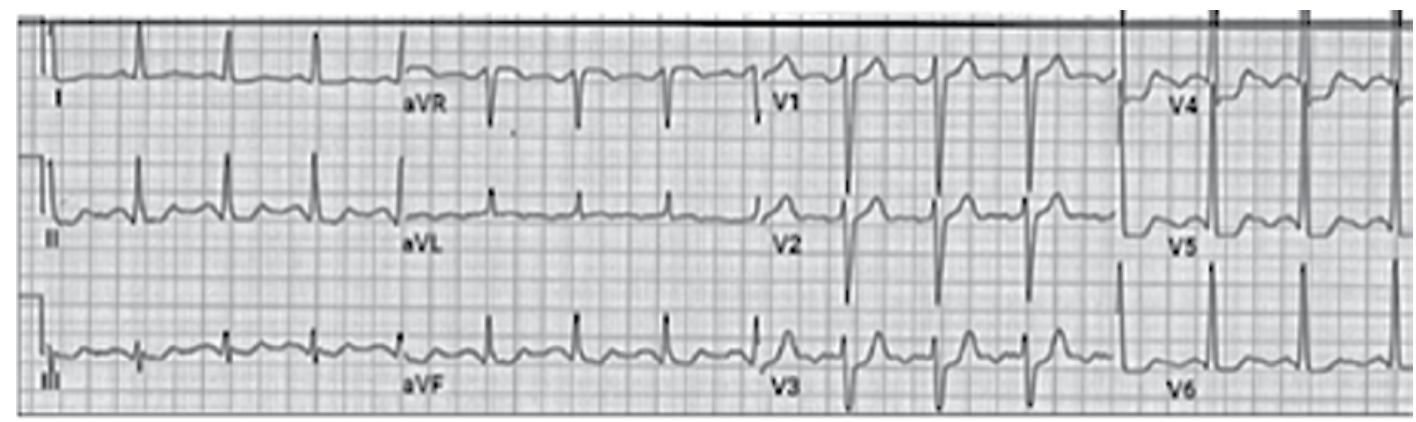

Figure 2: Inverted U waves in leads V3-V6 and aVL.

the difference in action potential duration, primarily of the functional refractory periods between the His-Purkinje system and the ventricular muscle in humans, do not explain the duration of $U$ wave, and that the small mass of the conducting system tissue might fail to produce the deflection. Other arguments are the existence of $U$ wave in amphibia, even though they do not have Purkinje fibers; ${ }^{3,11}$ and that the configuration of the $U$ wave is not concordant with the repolarization pattern of Purkinje fibers, among others. 5,6

\section{Repolarization of papillary muscles}

Furbetta, Bufalari, and Santucci considered that the $U$ wave corresponded to the repolarization of papillary muscles and the structures connected to them embryologically and functionally, primarily because of the results they obtained in experiments with dogs, where they found that the voltage of the $U$ was highest indirect leads from points of the ventricular surface near the origin of these muscles. ${ }^{2,15}$

They also described the «papillary muscles syndrome» resulting from cardiovascular diseases that specifically affect the papillary muscles with perfusion disruption, strain, or metabolism disturbances. The electrocardiographic signs group every alteration on the $U$ wave and de $\mathrm{T}-\mathrm{U}$ segment and are arranged in 3 possible patterns: left, right and biventricular papillary muscle syndrome. ${ }^{15}$ Nonetheless, arguments like the one posed by Surawicz, exposing that the differences between action potential durations of these structures are not sufficiently large to explain the typical duration of $U$ wave, also go against this theory. ${ }^{5}$

\section{3. $M$ cells theory}

The $M$ cells were first described in a dog's myocardium by Antzelevitch and Sicouri. They are a subpopulation of cells in the deep subepicardial to the mid myocardial portion of the ventricular wall with different electrophysiologic characteristics of those of the cardiac muscle and the conducting system. 4,16 The $M$ cells' theory was based on the fact that their action potentials are distinctly more prolonged than those of other myocardial cells. They fulfilled some of the points that contradicted other theories, among these is that the repolarization is long enough, at least at slow rates, to match the timing of the $U$ wave, and that the mass of $M$ cells appeared to be substantial to cause a deflection on the electrocardiogram, occupying up to $40 \%$ of the left ventricular wall in dogs and $30 \%$ in humans. The main conflicting issue with this hypothesis is that it meets all the requirements at marked slow heart rates; these cells are more likely to prolong the T-wave rather than create distinct U waves. $3,9,16,17$

\section{Mechanoelectrical theory}

This theory is based on the electrical manifestations of ventricular stretch, which could be explained by mechanosensitive ion channels, transducing mechanical stimuli on electrical changes, creating after-potentials and influencing repolarization timing. ${ }^{5}$

It states that the $U$ wave genesis is due to stretch-induced delayed after depolarization caused by the ventricular wall's distension during rapid ventricular filling. ${ }^{2,16,18,19}$ Surawicz 
Table 1: Most common conditions associated with changes in the $\mathrm{U}$ wave.

Negative U waves

Cardiac disease

- Coronary artery disease

- Hypertension

- Valvular disease

- Primary cardiomyopathy

- Left ventricular enlargement

- Congenital heart disease

Other conditions

- Hyperthyroidism

Normal

- $7 \%$ of the population has negative $\mathrm{U}$ waves without heart disease

Prominent $\mathrm{U}$ waves

Rhythms

- Bradycardia

- Complete heart block

- Congenital long QT syndrome

Cardiac disease

- Early repolarization

- Mitral valve prolapse

- Left ventricular enlargement

- Cardiomyopathy

- Circumflex-related myocardial infarction

Physical

- Hypothermia

- Forced inspiration

- After exercise

- Central nervous system/cerebral events

Electrolytes

- Hypokalemia

- Hypomagnesemia

- Hypocalcemia

Medications

- Class III antiarrhythmics

- Class IA antiarrhythmics

- Epinephrine

- Digitalis

- Phenothiazines

specified that the $U$ wave's appearance coincides with the isovolumic interval from the closure of the semilunar valves to the opening of the atrioventricular valves and the early diastolic interval. ${ }^{5,19}$

This explanation was supported mainly by the timing of the $U$ wave coincident with the time of ventricular relaxation. ${ }^{20}$ However, it was questioned because, with the advent of intracellular recording, it was noticed that, in general, normal cardiac cells did not generate after depolarizations, so they cannot explain the $U$ wave that appears under normal conditions (> $40 \%$ of adults). ${ }^{3,4}$ However, in the model of Di Bernardo et al., it was considered that afterpotentials could explain $U$ waves in normal subjects. They also affirmed that delaying repolarization in different regions of the heart cannot explain the $U$ wave. Although they found that after-potentials' presence does explain some of its characteristics, like the polarity, and that abnormal after-potential timing corresponds with abnormal $\mathrm{U}$ wave inversion (Figure 1). ${ }^{9}$

Next, we explain the most common conditions associated with changes in the $U$ wave (Table 1).

\section{INVERTED U WAVES}

Since the middle of the last century, it has been spoken about the importance of the inversion of the $U$ wave and negative $U$ wave. The $U$ wave has typically the same polarity as the $T$ wave, and it is clear that the $U$ wave inversion with an upright $\mathrm{T}$ wave has pathological significance. ${ }^{21}$

Few studies have been published on the prevalence and prognosis of negative $U$ wave. Holkeri et al. investigated the prevalence and prognostic significance of negative $U$-waves and other $U$-wave morphologies in a large general population sample with a follow-up of approximately 25 years. Primary endpoints were all-cause mortality, cardiac mortality, and sudden cardiac death, and secondary endpoint was hospitalization due to cardiac causes. $60.6 \%$ of the subjects had normal U-waves, $3.5 \%$ presented with negative $U$-waves (amplitude greater than or equal to $0.05 \mathrm{mV}$ ), and $15.4 \%$ with minor negative (less than 0.05 $\mathrm{mV}$ ) or discordant U-waves. They found that negative $U$-waves are often associated with older age and cardiovascular risk factors and that, in general, it is a marker of poor prognosis. 
Table 2: Types of inverted $\mathrm{U}$ waves and its relationship with coronary artery disease.

\begin{tabular}{ccc} 
Presentations & Characteristics & Relationship with coronary artery disease (\%) \\
\hline Discordance type I & Negative T wave with positive U wave & 64 \\
Discordance type II & Positive T wave with negative U wave & 46 \\
Concordant & Negative U and T waves & 88
\end{tabular}

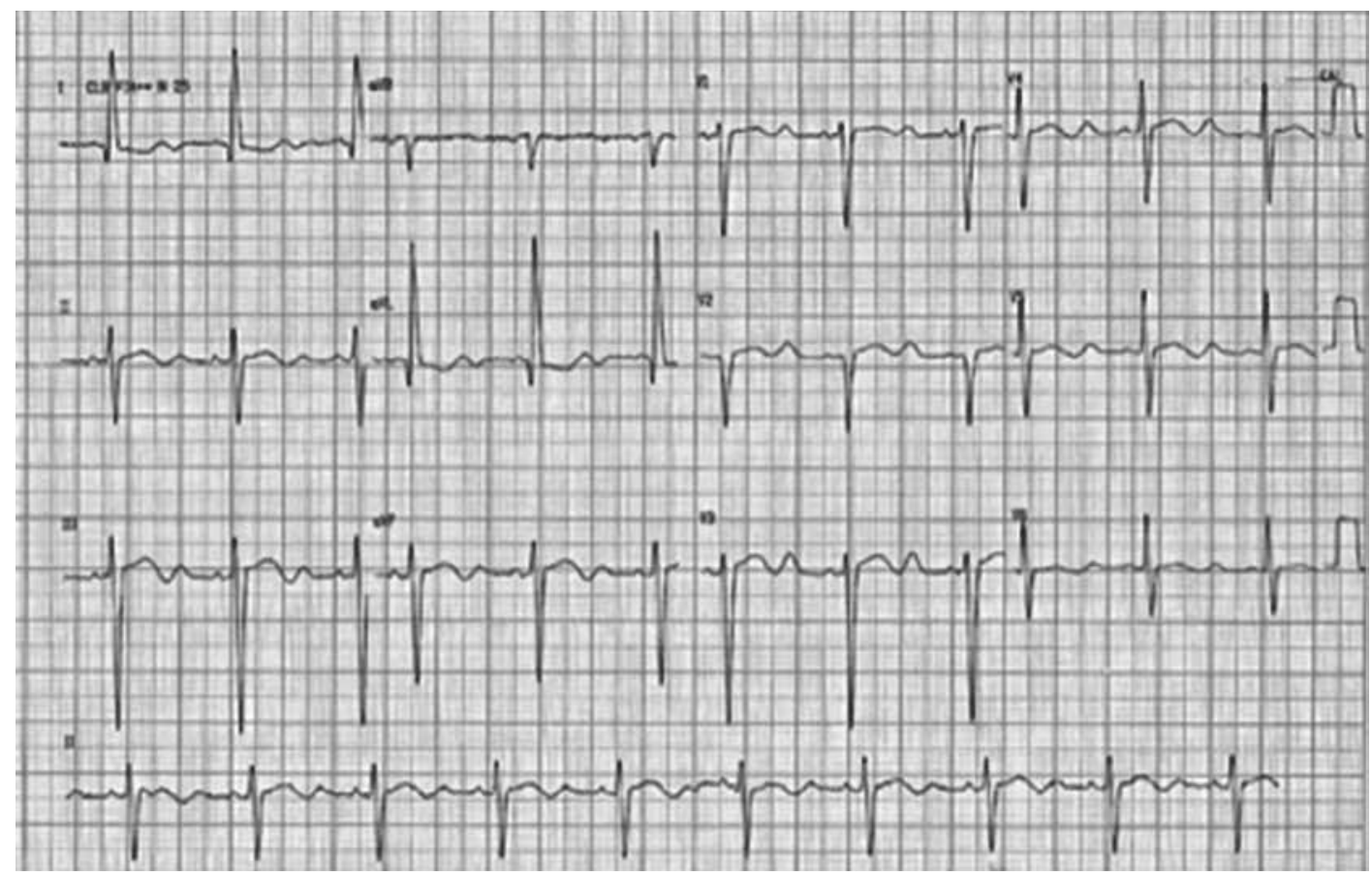

Figure 3: Prominent $U$ waves are seen in a patient with hypokalemia.

In men, this association is independent of cardiovascular risk factors, whereas women did not show a significant association to any of the endpoints. ${ }^{22}$

The most accepted pathophysiological mechanism to explain the appearance of inverted $U$ wave is related to prolonged ventricular diastole conditions. This is explained because prolonged stretching generates a delay in the activation of the channels that are activated by stretching, which generates a post potential and consequently a delayed post depolarization that is represented with the inverted $U$ wave in the electrocardiogram. ${ }^{9}$

There is no consensus on defining a significant inverted $U$ wave, but most studies and articles report that $U$ wave inversion was considered significant if there was a negative deflection of more than $0.05 \mathrm{mV}$ within the TP segment. ${ }^{6}$

An inverted $U$-wave is associated with abnormalities in $93 \%$ of cases. The main causes of negative $U$ waves are coronary heart disease, hypertension, valvular disease, congenital heart disease, hyperthyroidism and left ventricular hypertrophy. ${ }^{6}$

Usually, hypertension and coronary heart disease are the two most common diagnoses in which inverted $U$ waves are found. The negative $U$ wave is a transitory event lasting from minutes to months according to its cause and therapy. This transitory behavior proves the 
negative $\mathrm{U}$ wave to be a functional and not a structural change. ${ }^{23}$

In coronary heart disease, inverted $U$ waves have been described in 2 scenarios: epicardial coronary disease and vasospastic angina (Prinzmetal angina) (Figure 2).

\section{Epicardial coronary disease $^{7}$}

During acute ischemia, an abnormal relaxation pattern occurs. QT is prolonged, but mechanical systole shortens, explaining that the $U$ wave is produced during diastole. This discrepancy can vary during the acute scenario, which explains that the inverted $U$ wave can appear and disappear during acute ischemia. ${ }^{24}$

The inverted $U$ wave's clinical significance is that it may be the only finding of ischemia and can precede the appearance of typical STsegment and/or T wave changes.

The inverted $U$ wave helps locate the culprit's vessel and usually indicates extensive ischemia or stunning. The $U$ wave's inversion should suggest that the culprit vessel for myocardial ischemia is the anterior descending artery. $^{7}$ In $20 \%$ of patients with an anterior wall infarction, an inverted $U$ wave can be found, mainly in small infarctions, with less elevation of the ST-segment, better collateral circulation and a greater amount of stunned viable myocardium. ${ }^{6}$

$U$ wave inversion after exercise or exerciseinduced inversion of the $U$ wave is highly predictive of significant coronary artery disease and, more specifically, of disease of the proximal left anterior descending coronary artery. ${ }^{6}$ However, during a myocardial stress test, the appearance of an inverted $U$ wave has been associated with a lower likelihood of having extensive myocardial necrosis or complications when an acute occlusion occurs. This pattern probably indicates the presence of collateral circulation. ${ }^{25}$

Studies have shown that with the correction of the ischemia generated by a vessel occlusion, either by coronary arteriography or surgical revascularization, pathological changes in the $\mathrm{U}$ wave revert. ${ }^{26}$

It is important to establish the relationship between the $\mathrm{T}$ wave and the $\mathrm{U}$ wave; both waves can have the same polarity (concordant) or have different polarities (discordant). Below in Table 2 are the different presentations. ${ }^{8}$

\section{Vasospastic angina (Prinzmetal angina)}

The $U$ wave appears during the time of vasospasm. It has been found that during treatment with drugs to decrease vasospasm, such as calcium channel blockers, the $U$ wave disappears. In this type of angina, the inversion of the $U$ wave does not locate the compromised vessel. 6,27

Arterial hypertension explains $40 \%$ of the causes of $U$ waves. The appearance of $\mathrm{U}$ wave is related to poor blood pressure control. ${ }^{23}$ It has also been associated with poorly controlled hypertension leading to left ventricular hypertrophy. Therefore, the presence of an inverted $U$ wave is an indirect sign of left ventricular hypertrophy. Usually more evident in leads $\mathrm{V} 5$ and $\mathrm{V} 6{ }^{6}{ }^{6}$

The inversion of the $U$ wave in the left precordial leads is associated with aortic and mitral regurgitation because of left ventricular volume overload and left ventricular growth. The inversion of the $U$ wave in the right precordial leads is associated with right chambers growth. ${ }^{6}$

\section{PROMINENT U WAVES}

They are several definitions in the literature concerning the prominent $U$ waves; some of them will be explained below:

1. The $U$ wave reaches an amplitude of 0.1 to $0.2 \mathrm{mV}$ in lead $\mathrm{V} 3$, recalling that the $U$ wave's usual mean amplitude is $0.33 \mathrm{~mm} .^{12}$

2. U wave with an amplitude generally less than one-fourth of the preceding $T$ wave height. ${ }^{10}$

3. $\mathrm{U}$ wave that reaches an amplitude of 1.5 $\mathrm{mm}$ or more; however, there may be normal $U$ waves of up to $2 \mathrm{~mm}(0.2 \mathrm{mV})$ in the lead II, V2, V3 and V4. ${ }^{6}$

It is important to accentuate that the $U$ wave voltage is inversely proportional to heart rate and that a prominent $U$ wave may also be referred to in the literature as elevation of the $\mathrm{U}$ wave, tall $\mathrm{U}$ wave or high $\mathrm{U}$ wave. ${ }^{6}$ 
$U$ waves are essential to distinguish from bimodal or notched $\mathrm{T}$ waves, in which the second $\mathrm{T}$ wave apex is called T2; the latter must be at a distance from the first one $(\mathrm{T} 1)<150$ $\mathrm{ms}$; the $\mathrm{T} 1-\mathrm{U}$ interval is $>150 \mathrm{~ms}^{6}{ }^{6}$

Several pathologies have been associated with the development of prominent $U$ waves, as a follow are mentioned:

When the heart rate is $\leq 65 \mathrm{bpm}, \mathrm{U}$ waves are found in $90 \%$ of cases; ${ }^{6}$ in bradycardia, the $U$ wave is best observed or can appear as afterdepolarizations, ${ }^{4}$ it becomes more difficult to find in tachyarrhythmias as the other waves overlap the $U$ wave. ${ }^{12}$

In the early repolarization variant, bradycardia is commonly found, and $U$ waves are usual and best observed in lead V3. ${ }^{6}$

In long QT syndrome, prominent $U$ waves may represent early afterdepolarizations produced in Purkinje fibers and/or the ventricular muscle. ${ }^{4}$ The combination of a long QTU syndrome and «torsade de pointes» is the development of the fatal arrhythmia, which is usually preceded by bradycardia or pauses, in which the prominent $U$ can be seen. This pattern is also called «pause-dependent long QT syndrome». ${ }^{4}$ A channelopathy affecting inward rectifier potassium I (K1) channels (Andersen-Tawil syndrome) presents with prominent $\mathrm{U}$ waves, QT prolongation, and ventricular tachycardia. ${ }^{6}$

Hypokalemia can present prominent afterdepolarization potentials or unequal prolongation of the $\mathrm{M}$ cell action potential, ${ }^{17}$ producing prominent $U$ waves in the surface ECG $;{ }^{9}$ others consider that the $U$ wave is unchanged. The wave that really changes is the $T$ wave, as it fades to a small size making the $U$ wave is more noticeable, ${ }^{19}$ or that in hypokalemia, the $U$ wave is a consequence of the slowed phase 3 of the action potential, giving rise to small opposing voltage gradients that extend across producing a low amplitude bifid T wave. 6,10

It is important to recall that hypokalemia can be found in familial periodic paralysis syndrome, alkalosis or more common in prolonged episodes of diarrhea or vomiting, especially if are treated with intravenous infusions with low electrolyte count, and diabetic coma treated with high doses of insulin. ${ }^{18}$
Other electrolyte alterations, such as hypomagnesemia $(<1.8 \mathrm{mmol} / \mathrm{L})$ and hypocalcemia, can present prominent and alternant $U$ wave with ventricular irritability. ${ }^{6}$

Hypothermia creates a marked increase in the difference in the action potential duration of Purkinje fibers, and ventricular muscle fibers the phase 2 was greatly prolonged with low temperature $\left(32^{\circ} \mathrm{C}\right)$ and even more with lower heart rates $(60 \mathrm{bpm})$ and the duration of phase 3 is also markedly increased by lowering the potassium concentration. ${ }^{14}$

When using epinephrine, an early appearance of a prominent $U$ wave is seen. It starts on the T wave's descending branch; this can be explained by the related hypokalemia the medication produces because of an increase in potassium permeability; this can be prevented by administering potassium previously or concomitantly with epinephrine. ${ }^{2}$

Other medications such as digitalis can increase the voltage of the $U$ wave, with no change in its polarity, explained by an inhibition of reabsorption of potassium during diastole; this effect can be magnified by the fact that digitalis lower heart rate, and as explained above, bradycardia is an environment that facilitates the identification of the $U$ wave. ${ }^{18}$

All medications that increase the amplitude of the negative after-potentials increase ventricular excitability, thus generating $U$ waves. ${ }^{18}$ They can be classified as class III antiarrhythmics (amiodarone, dofetilide, sotalol) and class IA antiarrhythmics (quinidine, disopyramide and procainamide). ${ }^{6}$ Quinidine increases the amplitude of the $U$ wave by disproportionate prolongation of the $M$ cell action potential ${ }^{2,17}$ also discreetly prolongs the QRS complex and the QTC interval with torsade de pointes tendency and depressed, widened, notched, and inverted $\mathrm{T}$ wave. Phenothiazines have similar electrocardiographic effects as quinidine. ${ }^{6}$

Myocardial infarction can also present elevation of $U$ waves, and this is usually seen in the acute phase when the ST-segment is elevated. In the last phase, when the ST-segment decreases, the $U$ wave remains upright or, in the minority of cases, becomes inverted. ${ }^{2}$ This finding is seen in posterior myocardial infarction due to circumflex occlusion in the 6-24 hours period since the onset of symptoms. ${ }^{6}$ 
Endocranial hypertension due to alterations of the central nervous system can present with augmented $\mathrm{T}$ and $\mathrm{U}$ waves; as both are increased, the $T / U$ ratio does not change. ${ }^{6}$

Prominent $U$ waves can be found in the after-exercise context, explained by the appearance of afterdepolarization potentials. ${ }^{18}$

Other situations such as forced inspiration, mitral valve prolapse, acquired complete atrioventricular block, left ventricular enlargement, and hypertrophic cardiomyopathy with solitary hypertrophy of papillary muscle can course with prominent $U$ waves. ${ }^{6}$

It is believed that the severity of the underlying cause of the $U$ wave is correlated with the type of $U$ wave generated in the surface ECG, and as the alteration regress, the $U$ wave may disappear or, by the contrary, may progress if the underlying cause persist (Figure 3). ${ }^{15}$

\section{CONCLUSIONS}

Even though the $U$ wave may be forgotten and there are still many gaps in its understanding. Today we have more information that allows us to identify when it occurs under normal circumstances or when its characteristics guide us to identify possible abnormalities, recognizing it as a valuable tool to support the diagnosis of specific pathologic conditions. The $U$ wave must continue to be the subject of investigations and reports to continue enriching the associations and relationships with diseases and conditions of humans.

\section{REFERENCES}

1. Einthoven W. The telecardiogram. Am Heart J. 1957; 53 (4): 602-615.

2. Lepeschkin $\mathrm{E}$. VI genesis of the $U$ wave. Circulation. 15: 77-81.

3. Lazzara R. The $U$ wave and the $M$ cell. J Am Coll Cardiol. 1995; 26 (1): 193-194.

4. Antzelevitch C, Sicouri S. Clinical relevance of cardiac arrhythmias generated by afterdepolarizations. Role of $M$ cells in the generation of $U$ waves, triggered activity and torsade de pointes. J Am Coll Cardiol. 1994; 23 (1): 259-277.

5. Surawicz B. U wave: Facts, hypotheses, misconceptions, and misnomers. J Cardiovasc Electrophysiol. 1998; 9 (10): 1117-1128.

6. Pérez RAR, Ferreira $C$, Ferreira FC, Ferreira $M$, Meneghini A, Uchida $\mathrm{AH}$ et al. The enigmatic sixth wave of the electrocardiogram: the $U$ wave. Cardiol J. $2008 ; 15$ (5): 408-421.

7. Correale E, Battista R, Ricciardiello V, Martone A. The negative $U$ wave: A pathogenetic enigma but a useful, often overlooked bedside diagnostic and prognostic clue in ischemic heart disease. Clin Cardiol. 2004; 27 (12): 674-677.

8. Reinig MG, Harizi R, Spodick DH. Electrocardiographic $\mathrm{T}$ - and $\mathrm{U}$-wave discordance. Ann Noninvasive Electrocardiol. 2005; 10 (1): 41-46.

9. Di Bernardo D, Murray A. Origin on the electrocardiogram of $\mathrm{U}$-waves and abnormal $\mathrm{U}$-wave inversion. Cardiovasc Res. 2002; 53 (1): 202-208.

10. Hlaing T, DiMino T, Kowey PR, Yan GX. ECG repolarization waves: Their genesis and clinical implications. Ann Noninvasive Electrocardiol. 2005; 10 (2): 211-223.

11. Ritsema Van Eck HJ, Kors JA, Van Herpen G. The $U$ wave in the electrocardiogram: A solution for a 100-year-old riddle. Cardiovasc Res. 2005; 67 (2): 256-262.

12. Hannibal GB. The mysterious u wave. AACN Adv Crit Care. 2016; 27 (3): 344-346.

13. Beach D. Brief reviews. J Music Theory. 1966; 10 (1): 172.

14. Watanabe Y. Purkinje repolarization as a possible cause of the $U$ wave in the electrocardiogram. Circulation. 1975; 51 (6): 1030-1037.

15. Bufalari A, Furbetta D, Santucci F, Solinas P. Abnormality of the $U$ wave and of the T-U segment of the electrocardiogram; the syndrome of the papillary muscles. Circulation. 1956; 14 (6): 11291137.

16. Craik C. NIH Public Access. Bone. 2008; 23 (1): 1-7.

17. Nesterenko VV, Antzelevitch C. Simulation of the electrocardiographic $U$ wave in heterogeneous myocardium: effect of local junctional resistance. Proc-Comput Cardiol CIC 1992. 1992; 43-46.

18. Westhorpe RN, Ball C. The electrocardiogram. Anaesth Intensive Care. 2010; 38 (2): 231.

19. Eyer K. Support for a mechanico-electrical source of the " $u$ " wave. J Electrocardiol. 2015; 48 (1): 31-32.

20. Schimpf R, Antzelevitch C, Haghi D, Giustetto C, Pizzuti A, Gaita F et al. Electromechanical coupling in patients with the short QT syndrome: further insights into the mechanoelectrical hypothesis of the $\mathrm{U}$ wave. Heart Rhythm. 2008; 5 (2): 241-245.

21. Conrath CE, Opthof T. The patient $U$ wave. Cardiovasc Res. 2005; 67 (2): 184-186.

22. Holkeri A, Eranti A, Haukilahti MA, Kerola T, Kentta TV, Noponen $\mathrm{K}$ et al. Prevalence and Prognostic Significance of Negative $U$-waves in a 12-lead Electrocardiogram in the General Population. Am J Cardiol [Internet]. 2019; 123 (2): 267-273. Available in: https://linkinghub.elsevier.com/retrieve/pii/ S0002914918319647

23. Miwa K, Miyagi Y, Fujita M, Fujiki A, Sasayama S. Transient terminal $U$ wave inversion as a more specific marker for myocardial ischemia. Am Heart J. 1993; 125 (4): 981-986.

24. Nagayoshi Y, Yufu T, Yumoto S. Inverted U-wave and myocardial ischemia. QJM. 2018; 111 (7): 493. 
25. Kishida H, Otsu F, Suzuki K, Hata N, Kusama Y, Suzuki $T$ et al. Prominent Negative $U$ Wave in variant angina pectoris. Jpn Heart J. 1985; 26 (6): 885-896.

26. Salmasi AM, Salmasi SN, Nicolaides AN, Vecht RJ, Hendry WG, Kidner PH et al. The value of exercise-induced $U$-wave inversion on ECG chest wall mapping in the identification of individual coronary arterial lesions. Eur Heart J. 1985; 6 (5): 437-443.

27. Miwa K, Murakami T, Kambara H, Kawai C. U wave inversion during attacks of variant angina. Br Heart J. 1983; 50 (4): 378-382.
Funding source: This research has not received any specific grant from agencies in the public, commercial, or non-profit sectors

\section{Conflict of interests: None}

\section{Correspondence:}

Laura Lopera Mejía

E-mail: lauraloperam@hotmail.com 